\title{
Beyond Two Decades of Motivation: A Review of the Research and Practice in Instructional Design and Human Performance Technology
}

\author{
PATRICIA L. HARDRÉ \\ University of Oklahoma
}

\begin{abstract}
Existing models and methods of instructional design and performance improvement offer promise for enhancement in nearly every area of human resource development. However, they fall short of potential in addressing human motivation in ways that enable workplace performers and their organizations to thrive. This article reviews dominant models for instructional design and human performance technology currently in use, and compares their treatment of motivation in light of recent research in human motivation. The review illustrates an implementation gap between what research demonstrates about human motivation and what current instructional design models make available for use in workplace learning and development. It further underscores the need for a new, integrative, systemic model of motivation to aid in designing instruction by implementing recent research principles in workplace contexts. It calls for a new model of motivation for instructional design that is current, comprehensive, integrative, and flexible to meet the demands of new paradigm human resource development.
\end{abstract}

Keywords: instructional design models; motivation; systems approach; human resource development; human performance technology

Instructional design, human performance technology, and human resource development share origins, goals, and characteristics that illustrate the need for these fields to be clearly aligned. All three are relatively young academic disciplines built on well-established fields of professional practice (see Reigeluth, 1999; Stolovich \& Keeps, 1999; Swanson \& Holton, 2001). All are concerned with human development and functioning and focus on learning and performance as critical outcomes (see Reigeluth, 1999; Stolovich \& Keeps, 1999; Swanson \& Holton, 2001). All three involve processes that offer potential to develop employees' knowledge, expertise, and affective characteristics, and thereby positively influence productivity, retention, and

Human Resource Development Review Vol. 2, No. 1 March 2003 54-81 DOI: $10.1177 / 1534484303251661$

(C) 2003 Sage Publications 
workplace climate (see Reigeluth, 1999; Stolovich \& Keeps, 1999; Swanson \& Holton, 2001). These three fields operate on sets of flexibly adaptive, contextually sensitive core principles applied to the needs of various and changing situations to achieve target goals and add value to the organization (see Reigeluth, 1999; Stolovich \& Keeps, 1999; Swanson \& Holton, 2001). All three fields of practice have developed to align with distinctly new philosophical frameworks characterized as new paradigm (Reigeluth, 1999) or second stream (Swanson \& Holton, 2001) approaches that focus on developing human potential in ways that address the needs and influences within the whole organization.

\section{The Instructional Design (ID)-Human Resource Development (HRD) Interface}

Two points of the ID decision-making process are particularly critical to HRD. One is whether instruction is the appropriate strategy (if the need exists to update, remediate, or refine skills vs. to support existing skills), and the other is what the nature of that instruction is to be (the who, how, when, where, how long, what methods, etc.). The first decision is dependent on an initial analysis of the issues and contexts of performance, which is in turn dependent on the human performance technology (HPT) model in place in the organization. It is the HPT method that determines whether systematic, comprehensive analysis occurs, and whether training or other interventions (e.g., performance support, environmental change) may be effective solutions (Harless, 1980; Reigeluth, 1999; Rummler \& Brache, 1995). The ID method includes further analysis with consequent strategic design and development once the decision to instruct has been made (Reigeluth, 1999; Smith \& Ragan, 1993/1999). Because both levels of analysis and strategy are critical to optimizing human performance, both types of models are included in the analysis that follows.

The organizational performance paradigm takes in performance improvement at the individual, process, and organizational levels. It incorporates factors beyond individual performance improvement, such as organizational change, process redesign, and global policy, for example. The focus of this article is on HPT, on the human, individual performance improvement area of the overall performance paradigm, as distinguished from whole-system performance improvement (PI), although it assumes a systems view of the PI process.

The intent of this article is to compare the dominant models in ID and HPT, with a focus on their provision for assessing and addressing human motivation, to identify the existing gaps and the characteristics of a new model that would fill those gaps. The models discussed here were selected because they are prominent in the field, dominant in texts for education of 
ID and HPT professionals, and included in other discussions of motivation for ID (e.g., Keller, 1999). This set of models is not intended to be comprehensive but representative of the relevant models currently being used and taught in the fields of ID and HPT.

\section{State of the Current Models}

Although the field of ID has moved from its traditional, static, singleevent training model and broadened into synergy with the performance improvement paradigm of professional development, its motivation models have not. Nor have the major texts on HPT incorporated motivation research and practice explicitly into their intervention design approaches. Human resource efforts depend on human learning and performance for developing the potential value of human capital in the organization. The quality and effectiveness of ID methods largely determine the quality of resulting learning and performance. Therefore, the effectiveness of ID models with regard to motivation is critically important to human resource professionals.

Yet ID models have not integrated and incorporated research in motivation during the same period in which the three fields have moved together and in which research has developed in support of the new paradigm. Existing models and methods of performance improvement offer promise for enhancement in nearly every area of HPT. Current ID models provide for systematic analysis of task, content, and context in ways that support design of effective, efficient instruction. They offer access to varied strategies for designers to implement as appropriate based on analysis, and provide structure for complex design decision making, with clear goals and measurable objectives. However, they fall short of potential in addressing human motivation in ways that allow workplace performers to thrive. Human motivation is a key to optimizing the potential for learning and performance, because "it is people, with their ability to learn, who offer the greatest potential for organizational success" (Stolovich \& Keeps, 1999, p. 4). If motivation is critical to learning and performance, and learning and performance to organizational success, then to meet the human resource needs of organizations, ID must address the motivational needs of learners comprehensively.

\section{A Systems View of ID}

Although ID has traditionally operated on a closed-system model, its trend (within the framework of HPT) has moved toward viewing instruction (i.e., training, updating, remediating skills) as one subprocess in the larger open system of the organization (see Katz \& Kahn, 1966). It is the systems view provided by HPT that brings the goals of ID to focus within the organizational framework. Furthermore, the principles of ID come primarily from 
psychological research, and "systems theory and psychological theory align in the belief that organizations are composed of multi-minded individuals engaging in patterned activity" (Swanson \& Holton, 2001, p. 123).

Given the relationships of ID, HPT, and HRD, and the demands of newparadigm human resources (HR), the purpose of this article is twofold: (a) to identify the need for a new model of motivation for ID that will satisfy the demands of new-paradigm ID and meet the needs of today's HRD professionals, and (b) to identify four key requisites of such a model. To accomplish these goals, I will do the following: first, introduce the four requisites essential to such a model; second, argue for the benefits of explicit attention to motivation in ID; third, present a set of powerful self-processes that has been neglected in bringing the field up to date; and fourth, show how existing models fall short, leading to the call for a new model.

\section{Requisites of the New ID Motivational Model}

First, the model must be current (vs. outdated) in its treatment of human motivation. To do so, it must include the past 20 years of motivational theory and research. Research findings of the past two decades offer tremendous motivational assets to instructional designers, but the current tools do not include a large part of the recent cognitive findings and miss most of the potential of the self-processes from needs theory. These must be made current to bring ID solidly and coherently into the new paradigm.

Second, the model must include a comprehensive (vs. piecemeal) treatment of constructs and factors related to motivation. It needs to include the whole body of research, not just a single theory, or only behavioral theories as was considered adequate for ID operating on the training model. New paradigm ID needs to apply not just to direct-instruction settings or psychomotor and process skills but to myriad new technology-based learning environments and to addressing affect and human needs. To meet these demands, motivation in ID needs to account for not just external factors such as behaviors, incentives, and goals, but also internal processes and effects such as self-efficacy, control beliefs, causality, attributions, self-regulation, and self-determination. The previously discrete microtheories of motivation are coming together in the research, making this kind of comprehensive model possible now in practice.

Third, the model must be integrative (vs. eclectic) so that it pulls together fields of knowledge and makes sense of values and beliefs from the various traditional camps in useful ways. Instructional designers must address systemic issues and the macrolevel needs of organizations with a motivational model that acknowledges individual and situational differences. Today's ID must interface with as well as inform organizational methods and culture. The field needs an integrative model of motivation that takes into account 
individual and organizational factors so that it creates a smooth interface between general/educational psychology and industrial/organizational psychology and unites theory, research, and practice.

Fourth, the model must be flexible (vs. too rigid) so that it is adaptive to both HPT and ID and fits with rather than supplants designers' and performance technologists' existing design models. It should enable design in a range of applications and contexts, from direct-instruction in a small company to Web-based instruction for skill updates in a major multinational corporation, from field training for the military to in-house process management in a nonprofit service organization. Functionally, it will need to enable consistent and systematic design practice (vs. inconsistent or incidental approaches).

\section{The Enduring Problem of Motivation}

\section{The Implementation Gap}

Motivational issues are treated peripherally (or as assumables) in many of the historic assessment and intervention models, and the influence of motivational considerations during the analysis process itself is underrepresented in the research (Clark, 1997; Deci, Ryan, \& Williams, 1996). Some approaches (e.g., Rummler \& Brache, 1995) treat motivational issues as an afterthought, second to environmental issues like resource support and training, in formulating interventions. This may be due to a lack of understanding of the theory and research bases themselves (Clark \& Estes, 1998). Other methods (e.g., Robinson \& Robinson, 1996) identify motivation generally as crucial to learning and performance but treat it as a symptom, focusing on extrinsic features of the workplace context as sufficient, without direct attention to motivation itself. Without a theoretical grounding for understanding why instructional strategies succeed or fail, instructional designers are at a loss to explain or predict instructional outcomes (Noe, 1986). A large body of instructional research and some performance improvement systems models identify motivation as key determinants of performance (e.g., Gagne \& Medsker, 1996; Hiemstra \& Sisco, 1990; Keller, 1999; Rummler \& Brache, 1995). As a result, in theory and research, the literature contends that motivation is internal and important, whereas in practice motivation is treated as external and peripheral (or symptomatic). These realities represent a gap between assessment and implementation.

With the lack of clarity on why and how to design interventions that motivate employees, functional owners or managers may dismiss motivational issues as subjective choice or failures of character in workers (e.g., "doesn't care" or "lacks concern"), or they may accept amotivation as a stable trait of the worker (e.g., laziness or apathy) (Lohman, 1999; Sugrue, 1998). In such 
cases, the organization loses the potential for added value of motivation, which is improvable based on features of the workplace environment or learning opportunity linked by theory and research to target outcomes (Gagne \& Medsker, 1996; Hiemstra \& Sisco, 1990; Reeve, 1996).

Although their roots are in behaviorism, ID and PI have recently been influenced and enriched by cognitive science and learning theory research (Stolovich \& Keeps, 1999). In recent motivational developments, the trend is away from a primary focus on external rewards and incentives and toward an attentiveness to internal processes (such as beliefs, expectations, and attributions) (Reigeluth, 1999; Stolovich \& Keeps, 1999). Yet practice still lags behind the research, and the predominant proprietary models are less responsive. ID, with its roots in production-based training traditions and the military, lags behind HPT.

\section{Benefits of Explicit Attention to Motivation}

Historically, performance improvement and ID systems spoke to the need for interpersonal and motivational considerations, but with important limitations. They tended to address such issues after problems developed rather than as a part of front-end and instructional analysis (i.e., learner analysis). If instructional designers and performance improvement professionals treat motivation after the fact, they lose the potential for significant gain in training investments and risk wasting time and training resources. However, if analysts treat motivational assessment and intervention systematically, as they do such factors as knowledge components and information support resources, they can anticipate and prevent motivational deficits that undermine learning and performance.

Given the scarcity of resources and the costs of doing and improving business, we cannot afford to assume that even if our method is sound and we incorporate an inclusive, team approach, all the stakeholders will support performance improvement efforts. Motivation deficits, especially of those in pivotal positions, can produce self-defensive or self-defeating attitudes and behaviors that could undermine the improvement process at all levels (Deci, 1995; Keller, 1999; Locke \& Latham, 1990).

The benefits of motivationally enhancing performance contexts go beyond individual success and self-image, or even functional productivity. Positive, self-determined motivation among job performers results in job success and interest in the success of the organization, as well as continued or improved receptivity to training and development (Reeve, 1996; Williams \& Deci, 1998). The quality of interactions and contextual relationships among adults in a sociocultural setting directly influences their perceptions of and performances in that environment (Brookfield, 1986; Yelon, 1996), as well as their interest in and choice of workplace (Lawler, 1992; Reeve \& Deci, 
1996; Williams \& Deci, 1998). Support of individual and group success encourages a work environment perceived as safe for initiative and risk taking (Brougher, 1997; Reeve, 1999; Ryan \& Connell, 1989), which in turn promotes creativity and innovation (Gagne, 1985; Reeve, 1996; Yelon, 1996). These traits offer clear advantages in a competitive and ever-changing world market.

Motivation for learning and performance is not effective if isolated in the specialized context of the training environment. It must transfer to the postinstructional work environment where transfer and development are facilitated and supported. Attention to performance environment factors constitute the functional link between ID and human resource development, and HPT forms the interface. ID and PI professionals need to understand how workers and learners come to perceive events and conditions within environments and how they make choices related to those perceptions (Keller, 1999; Stolovich \& Keeps, 1999). Informing practitioners about the motivational consequences of environmental characteristics, and the motivational implications of external and internal factors, offers performance practitioners a more powerful means of influencing human learning and performance, and consequently supporting organizational goals (Stolovich \& Keeps, 2000).

\section{Developments in Motivation Theory and Research}

The past 20 years have seen an unprecedented amount of research and theory development in human motivation, generating findings that can powerfully support ID and HRD practice. Motivation to learn has been neglected in the workplace literature relative to its prominence in educational psychology research (Clark, Dobbins, \& Ladd, 1993), and although cognitive theories (e.g., goals, expectancies) have received increased attention in the workplace literature, process and affect have received less (Lawler, 2001). Yet affect and emotion are important in all interpersonal interactions, and specifically in workplace relationships, negotiation, collaboration, and teamwork (Lawler, 1992; Lawler \& Thye, 1999).

It is impossible to cover the whole body of research in this article, but it is possible to illustrate the need for and proposed nature of a new model of motivation for ID with a set of key components of motivation with important implications for HRD. These elements of motivation for learning and performance are strongly supported by psychological research but traditionally neglected in ID practice: intrinsic versus extrinsic motivation, self-efficacy and competence perceptions, causality and attributions, control beliefs, and self-determination. All of these characteristics are relevant to individuals and groups and can be influenced by motivational interventions (Clark, 1997; Eccles \& Wigfield, 1995; Reeve, 1996), and can be dependably 
assessed through direct observation, self-report or other-report questionnaires, and interviews. Given these characteristics, they constitute examples of factors important to HRD, accessible to assess and malleable via intervention, but neglected in existing ID models.

Motivation theories and research. Most researchers agree that motivation is an internal process that influences and regulates external behaviors, that it includes stable and malleable features, and that it can be influenced to some degree by intentional interventions (e.g., Deci, 1980; Gilbert, 1978/1996; Reeve, 1996; Schunk, 1991; Vygotsky, 1978; Weiner, 1986).

Until recently, theories of motivation were divided into at least two separate schools, often labeled as cognitive theories (e.g., goals, expectancies) and needs theories (e.g., self-efficacy, self-determination), with the former focused primarily on motivation related to academic and skills learning and the latter tending to focus on motivation as it related to affective and developmental issues (Graham \& Weiner, 1996; Pintrich \& Schunk, 1996; Reeve, 1996, 1999). More recently, cognitive and needs theorists have come to agree that the internal processes that underlie both learning and its related affective and motivational characteristics must collaborate for optimal performance to be achieved (Clark, 2000; Druckman \& Bjork, 1994; Keller, 1999). Cognitive theories have predominated in ID, although self-concept (self-process) theories offer additional potential to enhance learning and performance, especially where tasks are more variable (vs. well-defined) and systems interactions more complex (i.e., operating as open vs. closed systems).

Historically, various psychological mini-theories of motivation were treated in the scholarly community as discrete theoretical frameworks, each with its own body of research and principles, and the collective findings were rarely (if ever) overlaid (Reeve, 1996; Ryan \& Deci, 2000; see also Weiner, 1986, 1990). During about the past decade or so, however, theorists and practitioners have begun to explore integrating the mini-theories to understand commonalities among their constructs and develop a more integrative understanding of human motivation (Reeve, 1996, 1999; Ryan \& Deci, 2000). The result of this integration has been a synthesis of research into a more coherent set of applicable principles to translate into ID and HRD practice.

Intrinsic versus extrinsic motivation. One of the most important findings of the past two decades of motivation research is the differential effects and causes of intrinsic versus extrinsic motivation. Intrinsic motivation is positive, internalized, self-owned, high-quality motivation that promotes higher quality learning, better task performance, a more optimistic outlook, greater creativity and initiative, higher competence, reduced stress and tension, more productive adaptive approaches to challenge, and increased relatedness to others in the context (Ames \& Archer, 1988; Brookfield, 1986; Deci et al., 1996; Hiemstra \& Sisco, 
1990; Reeve, 1996). Extrinsic motivation is externalized, other-caused, low quality motivation that does not consistently facilitate those valued outcomes (Knowles, 1990; Pintrich \& Schunk, 1996). Intrinsic motivation is more effective and stable than extrinsic motivation (Brophy, 1998; Brougher, 1997; Deci \& Ryan, 1991; Reeve, 1996). Performers with an extrinsic motivational orientation tend toward challenge avoidance and pursuit of easy success, while those with intrinsic motivational orientations tend toward more challenge-seeking and risk-taking (Reeve, 1996; Shapira, 1976).

Ideally, every worker will perform better if the reason to work is joy in the task itself (Reeve, 1996), and the voluntary participation of learners and workers promotes a more open, positive work environment (Brookfield, 1986). However, most employees do not go to work purely for enjoyment of the job, which places them in a position of extrinsic motivation. Because intrinsic motivation is so beneficial to performance outcomes, and because contextual support of positive motivation tends to promote intrinsically motivated behavior (Deci et al., 1996; Rummler \& Brache, 1995), developing such contexts should be a front-end goal of performance improvement professionals.

Beyond its potential for enhancing individual performance, the distinction between intrinsic and extrinsic motivation has particular utility for human resource development. Often, a goal of organizational change and performance improvement is to enhance collaborative activity in the workplace. If the goal of performance improvement efforts is to facilitate cooperative behavior, it is counterproductive to use competition because competition undermines cooperative activity (Lawler, 1994). Altering external features of the environment may contribute to worker motivation temporarily or selectively, but interventions that contribute to integrated, intrinsic motivation translate into more lasting change (Deci et al., 1996; Gagne \& Medsker, 1996).

Control and the power hierarchy. Motivation is complex, both in its theoretical constructs and in its applications to learning and performance, but some aspects of motivation are especially sensitive within (and therefore influential for) HRD. Control issues are particularly problematic in employment relationships, given the power hierarchy (Reeve, 1996). Such relationships often include pressure, deadlines, and monetary incentives (or penalties) (Deci \& Ryan, 1987). Too often the attempt to motivate consists of external controls, when in fact such controls can actually undermine productive motivation (Vallerand, Fortier, \& Guay, 1997).

Control beliefs constitute a performer's expectation of his or her ability to influence outcomes (Reeve, 1996). Strong personal control beliefs promote mastery and high engagement, whereas loss of personal control results in helplessness, depression, demoralization, and disengagement (Deci, 1995). The value of personal control is considered "one of the most domi- 
nant and crucial human universals" (Brown, 1991). Organizations in which employees are given more personal control to an appropriate level tend to thrive (Kouzes \& Posner, 2002).

Self-determination. Self-determination drives perception of choice and control and is a basic human need (Deci, 1980; Ryan \& Deci, 2000). It is characterized by the desire to have personal choice determine behaviors and outcomes (autonomy), rather than to have those factors controlled by others (Deci \& Ryan, 1985; Reeve, 1998). Levels of self-determination are based largely on performers' attributions about their own power of choice and what actions actually bring change within their spheres of experience (Reeve, 1999; Reeve, Jang, Hardre, \& Omura, in press; Weiner, 1986). Learners and performers with a degree of process ownership display more positive attitudes toward the content, instructional process, and facilitator, as well as a greater desire to succeed (Hiemstra \& Sisco, 1990; Knowles, 1990). Self-determination is more specific than the related construct self-regulation, and is an internal process facilitating self-regulation (Ryan \& Deci, 2000). Self-determination and internal regulation are powerful motivational traits, which arise from personal and collective causality perceptions (Deci, 1980; Deci \& Ryan, 1985, 1987; Deci et al., 1996; Reeve, 1996; Ryan \& Grolnick, 1986).

Support of individual and group autonomy in instructional settings produces positive educational, developmental, social, and performance outcomes (Ames \& Archer, 1988; Deci \& Ryan, 1987; Hardre \& Reeve, in press). Conversely, failure to support autonomy (or an environment promoting control) of individuals within an organizational or instructional hierarchy reduces the potential for quality learning and skills mastery, limits creative and strategic initiative, and interferes with intrinsic motivation and development of prosocial behavior (Ames \& Archer, 1988; Ryan \& Connell, 1989; Vallerand et al., 1997).

Causality perceptions and attributions. Perceptions of causality identify whether people see themselves as authentically influencing the process and product of their work (Deci, 1995; Reeve, 1996). Causality perceptions are classified as internal or external, resulting in performers seeing themselves either as autonomous participants in actions (origins) or merely as tools controlled by others (pawns) (deCharms, 1976; Peterson \& Barrett, 1987; Ryan \& Grolnick, 1986). Factors within the work or learning environment can promote either kind of perception among performers (Reeve, 1996; Williams \& Deci, 1998). Causal attributions (explanations of why events occur) and explanatory style (how attributions are communicated) are primary indicators of control beliefs (Weiner, 1986). Motivation is substantially reduced when employees believe that their effort does not lead to improved performance and is increased when they believe that with effort their performance can improve (Deci, 1995; Latham \& Wexley, 2002; Peterson \& Seligman, 1984). 
The nature of attributions is expressed in an optimistic or pessimistic explanatory style, indicating how performers or learners see themselves in relation to causes of success or failure (Peterson \& Seligman, 1984; Taylor $\&$ Brown, 1994). In terms of job performance, employees with pessimistic styles tend to focus on causes of failure, see them as insurmountable, and give up, whereas those with optimistic styles tend to focus on remedies, see problems as surmountable, and persist in improvement (Diener \& Dweck, 1978; Mikulincer, 1988). The good news is that attributions can be changed, and retraining performers to make optimistic attributions can improve engagement, effort, and performance (Seligman, 1991).

Attribution theory research in general and educational psychology has focused on individual behavior, whereas in organizational psychology it has addressed collective attributions (Lawler, 2001). The contrast of internal and external attributions has framed much of the research over attribution theory, but attributions are also socially mediated (Lawler, 2001). These complex sets of influences underscore the need for a model that takes into account not just the narrow context of immediate instruction, as reflected in most ID approaches, but the larger scope of how learning and subsequent performance operate within the framework of the whole organization, the HPT view.

Self-efficacy. Self-efficacy is cognitive coping, the belief that the venture can succeed even in the face of challenges, and it causes people to put forth effort to achieve that success (Bandura, 1977). High self-efficacy enables learners and performers to persist and overcome obstacles and to achieve challenging goals (Bandura, 1993). Self-efficacy is more specific than self-esteem or selfconfidence, and its multiple dimensions are clearly linked to learning and performance (Bandura, 1997).

People with strong self-efficacy are able to consider the demands of the task, visualize successful strategies, and respond to challenges in positive, effortful ways, whereas performers with weak self-efficacy tend to focus on problems, expect failure, and lack flexibility to address problems that arise (Bandura \& Wood, 1989). People with high self-efficacy for a task are highly efficient in critical thinking and problem solving (Bandura \& Wood, 1989), but self-doubt impairs analytic thinking and flexibility for strategic problem-solving (Reeve, 1996). Strong self-efficacy beliefs produce effortful and persistent coping with setbacks and difficulties (Bandura, 1977; Salomon, 1984), whereas weak self-efficacy beliefs lead people to become discouraged or depressed, giving up when faced with problems (Bandura \& Cervone, 1983; Weinberg, Gould, \& Jackson, 1979).

The level of an individual's or group of performers' efficacy beliefs is always a function of the specific relationships between the performer(s) and task(s) (Folkman \& Lazarus, 1985). Some theorists and researchers have classified the concept of empowerment as a personal control issue, whereas 
others (e.g., Bandura) have identified it with self-efficacy. Efficacy is influenced by past performance, modeling, feedback, and physiological state (Bandura, 1993, 1997).

A critical distinction that underscores the potential of self-efficacy as a resource for ID and HRD is its complexity in terms of internal and external functions. Self-efficacy and competence are two different motivational issues, with implications in control and competence perceptions. The two concepts are sometimes divided between efficacy and effort (meaning subjective perceptions and enthusiasm for the task) and aptitude and competence (referring to actual/objective ability to perform) (Clark, 1997). However, competent functioning requires both task-specific ability to perform the requisite skills and functions related to a task and the cognitive capacity to translate those component skills (including contingency options) into effective performance in the face of challenging circumstances (Ford, 1996; Hardre, 2001a).

Individual self-efficacy is also tied to collective efficacy via relationships with others (Lawler, 2001), such that cognitive capacity is dependent on the interaction of individual, social, and contextual factors within the performance environment (Hardre, 2001c). Thus, self-efficacy is an ID and an HPT issue, of import to human resource goals. Self-efficacy theory has long been acclaimed, along with goal theory, as one of the potentially most powerful theories from educational psychology for workplace and industrial/ organizational psychology (Locke \& Henne, 1986), and although it has emerged more prominently in the workplace research, it is still underrepresented in the dominant ID models.

Competence. Competence and competence perceptions are foundational to all performance improvement, as any worker or learner must attain not only requisite skills but also some level of belief in the probable success of the venture (Gagne, 1985; Gilbert, 1978/1996; Williams \& Deci, 1998). The opportunity to engage in activity that offers optimal challenge activates a performer's sense of competence, and competence-communicating feedback promotes persistence of performance competence (Ozer \& Bandura, 1990; Reeve, 1996).

Within an authority-subordinate hierarchy, perceptions and behaviors of superiors, with regard to subordinates' competence, significantly influence performers' own competence perceptions (Kouzes \& Posner, 2002; Williams \& Deci, 1998). Competence communication by authority figures can facilitate improved competence perceptions among performers (Reeve, 1996; Williams \& Deci, 1998). Competence is a domain-specific, contextrelated demonstration of expertise (Swanson \& Holton, 2001). Human expertise can be operationally defined as domain-specific competence, which is both efficient and effective relative to the performance standard (Swanson \& Holton, 2001). 
Expectancies. In anticipation of an event or activity, performers typically spend time thinking about how they will perform (Reeve, 1998). A perception of the self as capable of succeeding promotes optimism and increases motivation to do well (Markus \& Nurius, 1986). Fear and expectations of failure reduce intrinsic motivation, initiative, and overall performance success (Dweck, 1986). Expectancies interact prominently with climate and value perceptions in shaping employees' motivation to work and learn (Clark et al., 1993; Keller, 1999; Lawler, 1994; see also Vroom, 1964).

Expectancies are among the best represented set of internal motivational features in the ID literature (along with cognitive goals and value). Keller's ARCS model (the individual letters of which stand for attention, relevance, confidence, and satisfaction) is the currently dominant model for ID, borrowed by all three major ID texts and many in HRD. Keller's model is based on Expectancy $\times$ Value theory (see Keller, 1983a).

Motivation as a complex phenomenon. Motivation is not a set of controllable, simple relationships between predictive conditions and predictable outcomes, but is a complex set of interactions among internal, external, interpersonal, and organizational dynamics (Hardre, 2001b; see also Stolovich \& Keeps, 1999). Functional interactions exist between individual perceptions, effort, and performance outcomes (Kanfer \& Heggestad, 1999).

In general, however, high perceptions of competence (Hardre \& Reeve, in press), high self-efficacy (Bandura, 1997), high perceived control (Gagne \& Medsker, 1996), and high self-determination (Deci, 1995) together constitute optimal motivational characteristics. Each of these characteristics can be positively influenced by interventions, based on understanding of their development and functioning. This fact underscores the value of intentional, systematic, research-based, outcome-specific interventions for motivational needs.

Self-processes interact with one another. For instance, even the combination of high self-efficacy and strong control perceptions are insufficient to affect lasting behavioral and motivational change, unless such change also arises from intrinsic choice (Ryan, 1982). Behaviors are self-determined not to the extent that they are reinforced but to the extent that they are based on, endorsed by, and congruent with the sense of self and identity (Deci \& Ryan, 1991; Rigby, Deci, Patrick, \& Ryan, 1992).

The complex interactions that influence employees' motivation are context-specific and responsive to organizational factors as well as to characteristics of tasks and levels of stress. For instance, performers' perceptions of their role in relation to organizational rules, standards, and decision making also increase motivation to succeed and vestedness in the success of others within the cohort (Locke \& Latham, 1990; Vallerand et al., 1997). How organizations and individual supervisors provide for and deliver feedback is particularly critical to employee motivation because the nature, fre- 
quency, timing, duration, and social context of feedback influence individual and group competence, perceptions, attributions, self-determination, self-efficacy, and expectancies (Keller, 1999; Latham \& Wexley, 2002; Reigeluth, 1999; Ryan \& Deci, 2000). Situational influences strongly influence choice behavior (Kanfer \& Heggestad, 1999).

These examples illustrate the importance of self-concept (process) theories of motivation (such as self-efficacy and self-determination) in addition to cognitive or agency theories for assessing and addressing motivation, especially when tasks are unfamiliar or stressful, and when goals or outcomes are uncertain (Sullivan, 1989). Thus, self-efficacy, competence, and control are closely linked. They are further influenced by regulation, which affects the initial malleability of motivation (Deci \& Ryan, 1987; Williams \& Deci, 1998). Additionally, they influence the stability of knowledge and performance improvement from interventions or training.

The critical role of perceptions. Some factors, such as efficacy, are defined by the learner's self-perception, in contrast to objective external measures. Other factors, such as competence, may have both an objective, measurable level and a level defined by learner perceptions. Worker perceptions of workplace climate and their decision involvement significantly affects their motivation to learn, skill transfer, and perceived job utility (Clark et al., 1993). Basing incentives and rewards to employees on outcomes and decisions over which they have little or no perceived control reduces motivation (see Latham \& Wexley, 2002) because employees' perceived control may differ from an objective assessment of control, and it is the perception that drives motivational outcomes. Perceptions are powerful.

Managers' versus employees' perceptions. Individual differences in experience and preferences influence workers' and learners' perceptions of features such as access and support within the environment (Reeve, 1999; Ryan \& Deci, 2000). What employees perceive-rather than what managers intenddetermines how the work or learning environment affects employees' motivation, and consequently their performance (Ryan \& Deci, 2000; Williams \& Deci, 1998). It is important for HR managers, instructional designers, and trainers to recognize two important things about worker and manager perceptions: (a) that the levels of these two factors may be different, and (b) if they are different, it is the learner's perception that influences actual learning and performance. The error often made by managers is to assume that what motivates them will also motivate their employees, rather than taking time to analyze and understand the values and preferences that underlie employees' motivations (Vroom, Herzberg, Kovach, \& Manz, 1989).

Even with anchors in psychological theory, and their demonstration in research, outcomes differ among individual performers, even from the same conditions (Ames \& Archer, 1988). Thus, even a well-established, static model of learning and performance cannot answer every need. The dynamic 
nature of learning and performance contexts calls for a flexible, problemsolving model of motivational analysis, design, and intervention strategies for HPT (Stolovich \& Keeps, 1999).

\section{What Is Missing in Existing Models}

\section{Models From HPT}

HPT models offer more integrative and comprehensive views of human performance than do many ID models, primarily because they include analysis prior to the decision to train. They enable the HR professional to view human performance in a broader way than do most ID models, including front-end analysis (Harless, 1980) that considers causal factors and nontraining interventions systematically across the organization. The models included here are Gilbert's Behavior Engineering Model, Robinson and Robinson's Performance Consulting Approach, and Rummler and Brache's Tri-Level Human Performance System. In the big picture, dominant HPT models address the macrolevel needs of business organizations, but they do not effectively address the microlevel issues of human motivation, in terms of being current, comprehensive, integrative, and flexible.

Gilbert's Behavior Engineering Model (BEM). Thomas Gilbert established the conceptual and structural framework for HPT with his BEM (1978/1996). $\mathrm{He}$ originated the use of multilevel analysis as a method for identifying and addressing issues surrounding human competence (Gilbert, 1978/1996). His six-cell Performance Matrix conceptualizes human performance as a function of stimulus, response, and consequences, at both the environmental and individual levels (Gilbert, 1978/1996).

Previous reviews have pointed out problems in implementing this model for motivation; for instance, Keller (1999) noted that Gilbert's model identifies "personal components" but "does not provide detailed coverage of motivational elements" (p. 376). The BEM does treat motivation (through motives and incentives) and does emphasize the importance of motivation as a factor of human capital (Gilbert, 1978/1996). It identifies the importance of competence information (which it calls "confirmation"; see Gilbert, 1978/1996, p. 309), and emphasizes the value of causal analysis over simplistic or overgeneralized "solutions," yet it supports tangible incentives as the primary motivational intervention. In his thinking, Thomas Gilbert was certainly ahead of his time, but he was also, to a degree, limited by it. This model was developed and published in the 1970s, based on behaviorism. It has not been updated to align with the past two decades of research (including the whole bodies of cognitive and needs theory research), so it falls short of the criteria of currency and comprehensiveness. 
Robinson and Robinson's Performance Consulting Approach. Robinson and Robinson's model (1996) proscribes an approach to causal analysis featuring skills/knowledge and environmental factors that influence human motivation, but it fails to address motivational needs directly. This approach does make some important distinctions, such as between competence and performance models, that provide for more precise understanding of the philosophies undergirding research and practice. As a macrolevel approach to viewing and addressing human performance, Robinson and Robinson's method offers tools useful to human resource professionals, but it does not provide the microlevel tools and information needed to address human motivation. In fact, it is difficult to locate Robinson and Robinson's position on motivation, because the term is not mentioned in the chapter on factors affecting performance, nor does it appear in the topical index of their book on performance consulting. In their lists of possible interventions, Robinson and Robinson do recommend some interventions with potential for motivational enhancement, such as "modifying rewards system" and "increase parameters for independent decision-making," but these are listed with no theoretical groundwork, little rationale, and no guidelines for assessment. The lack of specification for implementation makes it difficult for practitioners without preexisting knowledge and expertise in motivation to design and implement these interventions based on only the Performance Consulting Approach.

The treatment of motivation in this approach falls short of addressing the complexity of motivation and the nature of human interactions to the degree necessary to optimize learning and performance outcomes, or the level of detail necessary to adequately design motivational interventions. Thus, this model falls short of the criterion of being integrative as well as flexibly adaptive to both ID and HPT. Although Robinson and Robinson (1996) identify "research" as the foundation of their approach (p. 185), that research is not reported, nor is the model anchored in an explicit theory base. Thus, the model provided here lacks comprehensiveness in addressing human motivation for intervention design in performance improvement.

Rummler and Brache's Tri-Level Human Performance System. Rummler and Brache (1995) pointed out that a "good worker" can rarely succeed in a "bad system" (p. 64). On this premise, their human performance system focuses on features of the system. These authors claim (from experience) that "about $80 \%$ of performance improvement opportunities reside in the environment" (p. 73). Although they identify the importance of motivation as an underlying characteristic, they do not address it directly for analysis and intervention (see also Keller, 1999).

In its treatment of analysis at the Job-Performer level, Rummler and Brache's model (1995) does identify motivation as a "key performance variable" (p. 72). Yet it operates on the contention that motivation is a "symptom" (p. 72) and that attention to the six factors of the Human Performance 
System will automatically produce positive motivation. The six factors include two for performers (capacity and training) and four for the environment (clear expectations, task support, reinforcement of consequences, and appropriate feedback) (p. 72).

Although their estimate on the prevalence of environmental factors may be accurate, attention to contextual factors in an objective sense may not be sufficient to produce long-term gains in human motivation. If, as motivational research demonstrates, worker perceptions are a critical feature of the effects of environmental factors on actual performance outcomes, then analysis and design of environmental factors should take motivation specifically into account. If the full scope of motivational issues is not considered in performance analysis, development of interventions, implementation, and evaluation, then HPT professionals risk short-term, artificial "change." Although practitioners like Rummler and Brache chronicle their success in achieving performance improvement, we do not know how stable those improvements were, nor how they affected employee motivation.

The HPT professional who sees motivational issues intuitively or brings to the task some theoretical grounding will perhaps address motivational needs. But a methodology that leaves too much to individual expertise does not support the development of expertise for all practitioners. Too often serious motivational needs and issues remain unidentified and can undermine otherwise effective intervention strategies (Deci, 1995; Keller, 1999).

Rummler and Brache's system conceptualizes employees as one large, homogenous group, rather than individual people with individual needs and preferences. It may be appropriate for macrolevel thinking in which the goals focus on the global nature of organizations, but in treating motivation as a symptom, it ignores the two decades of research on human motivation. Given this characteristic, this model does not facilitate identifying needs and designing instruction that accounts for people factors; it falls short of being comprehensive. Furthermore, like Robinson and Robinson's approach, this model also falls short of being flexible enough to apply to ID. Thus, it is useful for executive/administrative goals, but not the full range of goals and purposes of human resource professionals. It simply does not meet the needs of the HR function.

Swanson's Performance Diagnosis Matrix. A potential supplement to Rummer and Brache's model, Swanson's Performance Diagnosis Matrix (Swanson, 1996) expands elements of the Human Performance System to include motivation explicitly at all three levels. Swanson's matrix offers "enabling questions" for analysis of performance issues at the organizational, process, and performer levels (p. 52). The questions specific to motivation address: (a) whether policies, culture, and reward systems support desired performance; (b) whether the process provides "information" and "human factors" required; and (c) whether the individual wants to perform, "no matter what" (p. 52). 
Swanson's approach adds to the tri-level systems model for HPT in explicitly addressing motivation. Furthermore, Swanson's model offers potential flexibility for both ID and HPT in that it includes various types of task analysis in the PI process, bringing systems thinking to the ID level. Thus, Swanson's matrix helps address the gaps of explicit attention to motivation and of ID/HPT flexibility left by Rummler and Brache. However, this approach also falls short of addressing motivation both currently and comprehensively, in that it does not provide research-based principles or identify the range of individual characteristics from which the user might gain information or design interventions. Thus, Swanson's model takes steps toward bridging the motivational gap in ID but does not satisfy the needs of the field.

\section{Models for ID}

ID models offer more detailed views of human performance than do the HPT models, focusing on design logic and decision making after the decision has been made to use an instructional intervention. ID models enable the HR professional to view human performance in a more precise way than through the broad lens of HPT. The models included here are Gagne's Training Model, and ID treatments of motivation from three textbooks dominant in postsecondary preparation of ID professionals: Morrison, Ross, and Kemp (2001); Dick, Carey, and Carey (2001); and Smith and Ragan (1993/ 1999). The goal of ID models is to equip instructional designers with the tools necessary for identifying and responding to instructional needs, but they do not effectively address the microlevel issues of human motivation relevant to ID. Even these dominant ID models fall short of addressing motivation, in terms of being current, comprehensive, integrative, and flexible.

Gagne's Training Model. Robert Gagne (1985) summed up the role of motivation in designing workplace instruction, as follows: "The job of the instructional designer is to assess the driving motives of individual learners or of typical learners in a group, and arrange learning activities to satisfy these motives" (p. 176). Gagne's ID method is built on "events of instruction," things that instructors and learners do during training. Gagne, in contrast to some other practitioners, does provide a theoretical basis for his approach to assessment and implementation, and identifies motivation as an essential consideration in performance analysis but defers to other texts for step-by-step implementation guidelines (Gagne \& Medsker, 1996, p. 14). Gagne's training approach includes Keller's (1983b) ARCS model for motivation to learn and solve problems, but Keller's model also addresses primarily a narrow band of motivational potentials.

Gagne's approach in borrowing Keller's model for motivation illustrates the practice of many ID professionals: Because their existing analysis and design models do not include motivation, they import and integrate specialty models of motivation to address these needs. Short of supplanting the 
existing models with an entirely new unifying approach (which is unlikely and currently unavailable), using Gagne's model requires importing a specialized model that is current, comprehensive, integrative, and flexible to address motivational needs while retaining the benefits of existing practice.

Morrison, Ross, and Kemp. Authoring one of the dominant texts for postsecondary professional preparation in ID, Morrison et al. (2001) offered no treatment of motivation as a component of ID or performance improvement. In fact, the term does not appear in the contents or index of their text. The "sequencing" section (chap. 6) treats "interest" briefly. Under learner analysis, there is no mention of motivation. Even the section on the affective domain only deals with inherent values and belief-driven practices related to "code of behavior" and "personality," but makes no link from beliefs or values to motivation to learn, engage, initiate, persist, or achieve. The focus of this approach is on marketing ID skill and practice to external customers. Like others who posit the designer as detached from the instructional context (e.g., Robinson \& Robinson, 1996; Rummler \& Brache, 1995), these authors bypass the whole body of motivation research and infer that learners' motivation will simply follow from technically well-designed instruction. With regard to addressing motivation for ID, this model is not current, comprehensive, integrative, or flexible.

Dick, Carey, and Carey. Dick et al. (2001) identify the motivational level of learners as the single most important factor in successful instruction (p. 97), and add that "teachers report that when learners have little motivation or interest in the topic, learning is almost impossible" (p. 97). However, these authors only offer one approach, Keller's ARCS model (detailed below) for addressing learner motivation within ID, and it is described in two paragraphs under "learner analysis" and then included in three other very brief illustrations elsewhere in the book. A single option treated this briefly and in relative isolation (vs. integration throughout) minimizes the importance of motivation to learning. This text's treatment of motivation in its ID model is not current, comprehensive, integrative, or flexible.

Smith and Ragan. Smith and Ragan's (1993/1999) guide to ID identifies the advantages of using a systematic approach to designing workplace instruction, including some factors attentive to workers' motivational needs. It advocates use of learning goals and active participation to facilitate learning. As a manual for general ID, Smith and Ragan's method (like Gagne's) focuses on instructional and training applications. It targets motivation as a subset of instructional strategy for attitude change, instead of as a global performance consideration. Like Gagne, as well as Dick and Carey, Smith and Ragan adopt and develop Keller's ARCS model, which becomes the structure for their motivational strategy sections. They then integrate motivational strategy development into methods for addressing learning goals based on types of knowledge to be gained, and add 
sections on attention strategies, confidence strategies, relevance strategies, and satisfaction strategies.

Like other models that import ARCS, this approach for ID is totally dependent on a single-theory, limited perspective of motivation. On its own, this treatment of motivation is not current, comprehensive, integrative, or flexible, and will only prove effective and efficient to the extent that the specialized model it borrows achieves those goals.

\section{Specialized Motivation Models}

Specialized models of motivation focus on and develop motivational considerations relevant to ID. Their function is to supplement models lacking their own treatments of motivation. One benefit of a specialized model for ID is that it can be revised and developed to keep pace with research, independent of revising the primary ID process model. Another benefit is that, if it is current, comprehensive, integrative, and flexible, a specialized motivation model can be imported into and integrated with multiple general ID models.

Keller's ARCS model. John Keller's (1983a) ARCS model of motivation for ID has stood as the dominant research-based motivational model across methods and applications (e.g., Alessi \& Trollip, 2000; Dick et al., 2001; Gagne \& Medsker, 1996; Smith \& Ragan, 1993/1999). The ARCS model is based on Expectancy $\times$ Value theory, a cognitive (vs. needs) theory. Keller's model is a useful tool, originally focused on the information delivery (instructional) component of ID and thus limited in its utility to HPT or HRD professionals.

More recently, Keller (1999) extended the model to encompass a broader theory base and a more global systemic view of designing motivational systems. He pointed out that the adequate explanation of human behavior must account for the ways that internal and external factors influence and interact with human behavior. Keller advocated addressing motivational issues holistically to lead to integrative, systemic solutions and appropriate balance of interventions. Unlike other systemic (HPT) models, Keller's distinguishes between the range of cognitive and motivational effects along continua of a single characteristic (e.g., facilitative vs. debilitating stress, and overconfidence vs. underconfidence). These are critical distinctions, given the findings of recent research on what previously were believed to be somewhat unitary psychological constructs.

Keller's problem-solving approach aligns with the global ID process and so enhances its potential for integrating with existing ID models lacking motivational components. Its recent expansion into the scope of HPT promotes flexible adaptivity to varying levels of analysis and intervention design. Of existing options, Keller's revised model holds the most promise for integrating current and future theory and research into motivationally 
optimal analysis, design and intervention for human performance and human resource goals. However, Keller's is a single-theory model, accounting for internal interactions between value and expectancies, but excluding other critical motivational constructs (e.g., self-determination, self-efficacy, and control perceptions). It falls short of being current and comprehensive across theoretical boundaries, assuming instead that the target outcomes it presents (attention, relevance, confidence, and satisfaction) will align with the outcomes valued by the instruction or organization. This narrow theoretical foundation is a limitation on the ARCS model.

Clark's CANE model: Richard Clark's (1997) CANE model highlights and addresses motivational gaps with a two-stage model of performer goal commitment and effort, applying some features of goal theory and self-efficacy theory to workplace learning and performance. Clark acknowledges the importance of performer perceptions of task-specific features like value, self-efficacy, and difficulty. He further identifies three variables influencing work commitment: goal value, emotions, and personal agency. From his discussion, we suppose that goal value includes relevance and applicability, that emotions includes access perceptions, and that personal agency includes efficacy and competence perceptions, although these are not clearly defined.

Clark does provide research bases for his categories and applications, as well as rationales for his assumptions of generalizability. In an appended chart, he lists potential problems, interpretations of "motive," and possible interventions that offer some potential for transfer across functions and settings. However, Clark's model focuses solely on the individual learner or performer (excluding social and organizational considerations) and it divides efficacy perceptions from competence without directing the practitioner on how to reintegrate them, two features which make his approach problematic. Clark suggests that assessing the cognitive approach to workplace functioning will allow the practitioner to select interventions to influence motivational gains, but he neglects to link the two parts of the process in an approach that transfers readily to multiple contexts. This lack is less a fault than a limitation of the "model" which is a tool for understanding the cognitive context of motivation, in contrast to a systematic method for strategic analysis and intervention.

In a separate publication, Clark (2000) offered a clearer treatment of motivation as it relates to cognitive functioning in HPT. The CANE model adds important elements to previously existing treatments of motivation for ID, but even its author recognized that it still does not meet all the needs of the field. It is current but not comprehensive in that it incorporates some aspects of multiple cognitive theories, but it falls short of taking into account the range of constructs and outcomes relevant to control perceptions, competence, self-efficacy, and self-determination. Since Clark is a cognitive theorist, his model leaves out the needs theories. The burden falls 
to the designer or HR professional to supply the missing pieces, which presents potential risk of eclecticism or incompleteness. The CANE model, like the revised ARCS model, expands ID implications into the scope of HPT, which enhances its potential to be flexible. Although it comes closer to the requisites, this model is not yet current, comprehensive, integrative, and flexible.

Related industrial/organizational models. Control perceptions have been linked to motivation in the leadership literature since the 1970s, when Vroom introduced a model that characterized leadership effectiveness in terms of shared decision-making power between leaders and subordinates (Vroom, 1977). Influential factors in this model include manager-level characteristics as the key to interactions influencing self-efficacy and self-determination. Vroom's leadership model focused on human interactions characterized by control versus autonomy, participation (inclusion), and performance feedback, and including competence perceptions as a target outcome. Vroom's model is not an ID model or a motivational model, but a leadership model that focuses on the behavior of those in superordinate positions and the consequences of that behavior for some motivational factors of their subordinates. It does, however, present an integrative, multitheory approach that suggests a possible structure for a new motivational model for ID and HPT, one that could include the various theories of motivation and further integrate theory and practice in ways that make sense for design and implementation. Similar to Vroom's integrative model including control perceptions, Locke and Henne (1986) offered an early organizational model (not an ID model) that included cognition, needs, values, goals/intentions, actions, and emotions as general factors.

\section{Conclusions and Future Directions}

The gap between need and implementation of motivational interventions is wide. Gilbert (1978/1996) and others have estimated that gains from motivational interventions (when implemented) in productivity alone can reach $70 \%$, and benefits in worker esteem, enthusiasm, and vestedness are frequently estimated at many times the costs of the interventions themselves (Clark, 2000; Clark \& Estes, 1998). Yet without effective models, designers and managers may continue to miss or circumvent deep analysis of performance problems and default to less effective interventions (Clark, 1997). The success of workplace instruction, whether initial skill training, update, remediation, or extension, depends for learning and performance on employee motivation.

The key to effectively addressing the motivational needs of performers and performance contexts lies in understanding the complexity of motivational dynamics and applying that understanding with sensitivity to relevant, context-specific factors. An essential perspective for analysts and 
designers to embrace is the critical role of the full range of motivational factors, including needs and perceptual components.

Some of the current ID models assume that employees' motivation will respond to environmental interventions designed without regard to motivational factors. Others require that designers bring specific expertise or intuitive approaches to motivation. Both are insufficient to meet the current challenges of ID and HPT and the needs of human resource professionals. The research demonstrates clearly that motivation is not assumable, but that it is amenable to strategic intervention.

Business owners and managers face the rising costs of doing business and of improving performance, the dynamics of rapidly shifting global markets, and the needs of an increasingly diverse workforce. Attention to motivational issues is more crucial than ever, especially as motivational considerations offer the potential to improve the stability and effectiveness of the whole body of human performance interventions. The fields of ID and HPT need a current, comprehensive, integrative, and flexible new model of motivation for intervention design.

Development of a model that satisfies these requisites will be challenging, but it is not impossible. To achieve the goals of being current and comprehensive in treating motivation, it will require a depth of knowledge and breadth of synthesis across theoretical boundaries. It will need not only to bring the field up to date by incorporating the past 20 years of research in motivation but also to make principles from that body of research accessible and useful to ID professionals. It will need to acknowledge differences in the way various "camps" have grounded their beliefs and defined critical constructs. It will need to pull together theory and research from organizational, instructional, and educational psychologies, including behavioral, cognitive, and needs-based theories, synthesize them, and draw out principles that practitioners can use to facilitate valued outcomes.

To achieve the goals of being integrative and flexible, it will require deeplevel analysis of: (a) existing ID models, so that it can align with their structures and processes; and (b) ID and HPT methods, so that it can address their multilevel goals. It will need to be functional as a tool for front-end analysis of motivation both before and after the decision to instruct has been made, to open doors to alternatives saving training costs.

The still-developing fields of ID and HPT need a clear, practical, functional model for integrating research-based principles of human motivation from across theoretical and disciplinary boundaries into all phases of performance improvement. Such a tool for performance improvement would serve as one way to improve HPT professionals' methodologies. It could aid in assessment to discover the nature of what Gagne termed driving motives, and in strategic intervention to identify more accurately what constitute Rummler and Brache's right conditions. It could facilitate HPT profession- 
als in moving beyond intuition and experience alone, and ground our practices more firmly in empirical research. It could make practitioners less dependent on commercial producers to supply rationales and enable us to more readily divide between gimmicks and serious tools of our practice. We may even be inspired to help fill the gaps with continued research of our own.

\section{Special Challenges for Research}

One step toward closing the gap between research and practice is practice that includes foundations in research, but another is research that facilitates practice. For ID and HPT, this means research that enhances clarity and facilitates application. Research should take place in authentic contexts, rather than trying to apply controlled lab studies piecemeal to the complex dynamics of instructional and performance contexts. Furthermore, research for ID should anchor in theoretical models that offer measurable outcomes and foster understanding of the relationships among constructs, rather than leaving practitioners with experiential estimates that do not either treat the complex construct of human motivation comprehensively or anchor findings in theory.

At the very least, a new, research-based model for tapping into motivation as a human resource may raise questions that we had not previously considered and lead us to investigate motivational issues in ways we have not before. If so, it will have contributed something of tremendous value to the fields of HPT and human resource development.

\section{References}

Alessi, S. M., \& Trollip, S. R. (2000). Interactive multimedia: Tools for learning and instruction. New York: Allyn \& Bacon.

Ames, C., \& Archer, J. (1988). Achievement goals in the classroom: Student learning strategies and motivational processes. Journal of Educational Psychology, 80, 260-267.

Bandura, A. (1977). Social learning theory. Englewood Cliffs, NJ: Prentice Hall.

Bandura, A. (1993). Perceived self-efficacy in cognitive development and functioning. Educational Psychologist, 28, 117-148.

Bandura, A. (1997). Self-efficacy: The exercise of control. New York: Freeman.

Bandura, A., \& Cervone, D. (1983). Self-evaluative and self-efficacy mechanisms governing the motivational effects of goal systems. Journal of Personality and Social Psychology, 45, 10171028.

Bandura, A., \& Wood, R. E. (1989). Effect of perceived controllability and performance on selfregulatin of complex decision-making. Journal of Personality and Social Psychology, 56, 805814.

Brookfield, S. D. (1986). Understanding and facilitating adult learning: A comprehensive analysis of principles and effective practices. San Francisco: Jossey-Bass.

Brophy, J. (1998). Motivating students to learn. New York: McGraw-Hill.

Brougher, J. Z. (1997, March-April). Creating a nourishing learning environment for adults using multiple intelligence theory. Adult Education, 28-29. 
Brown, D. E. (1991). Human universals. Philadelphia: Temple University Press.

Clark, C. S., Dobbins, G. H., \& Ladd, R. T. (1993). Exploratory field study of employee motivation. Group and Organizational Management, 18(3), 292-307.

Clark, R. E. (1997). The CANE model of motivation to learn and work: A two-stage process of goal commitment and effort. In J. Lowzck (Ed.), Trends in corporate training. Louvain, Belgium: University of Louvain Press.

Clark, R. E. (2000). The cognitive sciences and human performance technology. In H. D. Stolovich \& E. J. Keeps (Eds.), Handbook of human performance technology (2nd ed.). San Francisco: Jossey-Bass.

Clark, R. E., \& Estes, F. (1998). Technology or craft: What are we doing? Educational Technology, $38(5), 5-11$.

deCharms, R. (1976). Enhancing motivation: Change in the classroom. New York: Irvington.

Deci, E. L. (1980). The psychology of self-determination. Lexington, MA.: Lexington.

Deci, E. L. (1995). Why we do what we do. New York: Penguin.

Deci, E. L., \& Ryan, R. M. (1985). Intrinsic motivation and self-determination in human behavior. New York: Plenum.

Deci, E. L., \& Ryan, R. M. (1987). The support of autonomy and the control of behavior. Journal of Personality and Social Psychology, 53, 1024-1037.

Deci, E. L., \& Ryan, R. M. (1991). A motivational approach to self: Integration in personality. In R. Dienstbier (Ed.), Nebraska symposium on motivation: Perspectives on motivation (Vol. 38, pp. 237-288). Lincoln: University of Nebraska Press.

Deci, E. L., Ryan, R. M., \& Williams, G. C. (1996). Need satisfaction and the self-regulation of learning. Learning \& Individual Differences, 8(3), 165-185.

Dick, W., Carey, L., \& Carey, J. O. (2001). The systematic design of instruction (5th ed.). New York: Longman.

Diener, C. I., \& Dweck, C. S. (1978). An analysis of learned helplessness: Continuous chances in performance, strategy, and achievement cognitions following failure. Journal of Personality and Social Psychology, 36, 451-462.

Druckman, D., \& Bjork, R. A. (1994). Learning, remembering, believing: Enhancing human performance. Washington, DC: National Academy Press.

Dweck, C. S. (1986). Motivational processes affecting learning. American Psychologist, 41, 10401048.

Eccles, J., \& Wigfield, A. (1995). In the mind of the actor: The structure of adolescents' achievement task values and expectancy-related beliefs. Personality and Social Psychology Bulletin, 21, 215225.

Folkman, S., \& Lazarus, R. S. (1985). If it changes it must be a process: Study of emotion and coping during three stages of a college examination. Journal of Personaity and Social Psychology, 48, 150-170.

Ford, M. E. (1996). Motivating humans: Goals, emotions and personal agency beliefs. Newbury Park, CA: Sage.

Gagne, E. (1985). The cognitive psychology of school learning. Boston: Little, Brown.

Gagne, R. M., \& Medsker, K. L. (1996). The conditions of learning: Training applications. New York: Harcourt Brace.

Gilbert, T. F. (1996). Human competence: Engineering worthy performance. New York: McGrawHill. (Original work published 1978)

Graham, S., \& Weiner, B. (1996). Theories and principles of motivation. In D. Berliner \& R. C. Calfee (Eds.), Handbook of educational psychology. New York: Simon \& Schuster.

Hardre, P. L. (2001a, July). Building flexible technology skills: Concept models as instructional strategies for technological training. Performance Improvement, $40,6$.

Hardre, P. L. (2001b, July). Designing effective learning environments for continuing education. Performance Improvement Quarterly, 14, 3. 
Hardre, P. L. (2001c, Fall/Winter). Questions beyond context: Facilitating intentional, autonomous rehearsal, practice and application. Teacher Education and Practice, 14, 3.

Hardre, P. L., \& Reeve, J. (in press). A motivational model of rural students' intentions to persist in versus drop out of high school. Journal of Educational Psychology.

Harless, J. (1980). An ounce of analysis is worth a pound of objectives. Newnan, GA: Harless Press.

Hiemstra, R., \& Sisco, B. (1990). Individualizing instruction. San Francisco: Jossey-Bass.

Kanfer, R., \& Heggestad, E. D. (1999). Individual differences in motivation: Traits and selfregulatory skills. In P. L. Ackerman, P. C. Kyllonen, \& R. D. Roberts (Eds.), Learning and individual differences: Process, trait, and content. Washington, DC: American Psychological Association.

Katz, D., \& Kahn, R. L. (1966). The social psychology of organizations. New York: Wiley \& Sons.

Keller, J. M. (1983a). Development and use of the ARCS model of instructional design. Journal of Instructional Development, 10(3), 2-10.

Keller, J. M. (1983b). Motivational design of instruction. In C. M. Reigeluth (Ed.), Instructional design theories and models. Hillsdale, NJ: Erlbaum.

Keller, J. M. (1999). Motivational systems. In H. D. Stolovich \& E. J. Keeps (Eds.), Handbook of human performance technology (2nd ed.). San Francisco: Jossey-Bass.

Knowles, M. (1990). The adult learner: A neglected species. Houston, TX: Gulf Publishing.

Kouzes, J., \& Posner, B. (2002). The leadership challenge (3rd ed.). San Francisco: Jossey-Bass.

Latham, G. P., \& Wexley, K. N. (2002). Increasing productivity through performance appraisal. Menlo Park, CA: Addison-Wesley.

Lawler, E. E. III. (1994, May-June). Performance management: The next generation. Compensation \& Benefits Review, 16(3), 16-19.

Lawler, E. J. (1992, June). Affective attachments to nested groups: A choice-process theory. American Sociological Review, 57, 372-339.

Lawler, E. J. (2001). An affect theory of social exchange. American Journal of Sociology, 107(2), 321-352.

Lawler, E. J., \& Thye, S. R. (1999). Bringing emotions into social exchange theory. American Review of Sociology, 25, 217-244.

Locke, E. A., \& Henne, D. (1986). Work motivation theories. In C. L. Cooper \& I. Robertson (Eds.), International review of individual and organizational psychology. New York: John Wiley.

Locke, E. A., \& Latham, G. P. (1990). A theory of goal-setting and task performance. Englewood Cliffs, NJ: Prentice-Hall.

Lohman, M. (1999, March). [Lecture in challenges to performance improvement], University of Iowa College of Education.

Markus, H., \& Nurius, P. (1986). Possible selves. American Psychologist, 41, 954-969.

Mikulincer, M. (1988). The relationship of probability of success and performance following failure: Reactance and helplessness effects. Motivation and Emotion, 12, 139-152.

Morrison, G. R., Ross, S. M., \& Kemp, J. E. (2001). Designing effective instruction (3rd ed.). New York: Wiley.

Noe, R. A. (1986). Trainees' attributes and attitudes: Neglected influences on training effectiveness. Academy of Management Review, 11, 736-749.

Ozer, E. M., \& Bandura, A. (1990). Mechanisms governing empowerment effects: A self-efficacy analysis. Journal of Personality \& Social Psychology, 58, 472-486.

Peterson, C., \& Barrett, L. C. (1987). Explanatory style and academic achievement among university freshmen. Journal of Personality and Social Psychology, 53, 603-607.

Peterson, C., \& Seligman, M. E. P. (1984). Causal explanations as a risk factor for depression: Theory and evidence. Psychological Review, 91, 347-374.

Pintrich, P. R., \& Schunk, D. H. (1996). Motivation in education. New York: Merrill.

Reeve, J. (1996). Motivating others. Needham Heights, MA: Simon \& Schuster.

Reeve, J. (1998). The interest-enjoyment distinction in intrinsic motivation. Motivation and Emotion, 13, 83-103. 
Reeve, J. (1999, Spring). [Advanced seminars in human motivation], University of Iowa College of Education.

Reeve, J., \& Deci, E. L. (1996). Elements of the competitive situation that affect intrinsic motivation. Personality and Social Psychology Bulletin, 11(1), 24-33.

Reeve, J., Jang, H., Hardre, P. L., \& Omura, M. (in press). Motivating students to learn uninteresting but important lessons. Motivation \& Emotion.

Reigeluth, C. M. (1999). What is instructional design theory, and how is it changing? In C. M. Reigeluth (Ed.), Instructional-design theories and models, Volume II: A new paradigm of instructional theory. Hillsdale, NJ: Erlbaum.

Rigby, C. S., Deci, E. L., Patrick, B. C., \& Ryan, R. M. (1992). Beyond the intrinsic-extrinsic dichotomy: Self-determination in motivation and learning. Motivation and Emotion, 16(3), 165-185.

Robinson, D. G., \& Robinson, J. C. (1996). Performance consulting. San Francisco: BerrettKoehler.

Rummler, G. A., \& Brache, A. P. (1995). Improving performance. San Francisco: Jossey-Bass.

Ryan, R. M. (1982). Control and information in the intrapersonal sphere: An extension of cognitive evaluation theory. Journal of Personality \& Social Psychology, 43, 450-461.

Ryan, R., \& Connell, J. P. (1989). Perceived locus of causality and internalization: Examining reasons for acting in two domains. Journal of Personality \& Social Psychology, 57(5), 749-761.

Ryan, R. M., \& Deci, E. L. (2000). Self-determination theory and the facilitation of intrinsic motivation, social development, and well-being. American Psychologist, 55(1), 68-78.

Ryan, R. M., \& Grolnick, W. S. (1986). Origins and pawns in the classroom: Self-report and projective assessments of individual differences in children's perceptions. Journal of Personality and Social Psychology, 50, 550-558.

Salomon, G. (1984). Television is "easy" and print is "tough": The differential investment of mental effort in learning as a function of perceptions and attributions. Journal of Educational Psychology, 76, 647-658.

Schunk, D. H. (1991). Self-efficacy and academic motivation. Educational Psychologist, 26, 207-231.

Seligman, M. E. P. (1991). Learned optimism. New York: Knopf.

Shapira, Z. (1976). Expectancy determinants of intrinsically motivated behavior. Journal of Personality and Social Psychology, 34, 1235-1244.

Smith, P. L., \& Ragan, T. J. (1999). Instructional design. Upper Saddle River, NJ: Prentice Hall. (Original work published 1993)

Stolovich, H. D., \& Keeps E. J. (1999). What is human performance technology? In H. D. Stolovich \& E. J. Keeps (Eds.), Handbook of human performance technology (2nd ed.). San Francisco: Jossey-Bass.

Sugrue, B. (1998, November). [Lectures on instructional design], University of Iowa College of Education.

Sullivan, J. J. (1989). Self theories and motivation. Journal of Management, 15(2), 345-363.

Swanson, R. A. (1996). Analysis for improving performance. San Francisco: Berrett-Koehler.

Swanson, R., \& Holton, E. (2001). Foundations of human resource development. San Francisco: Berrett-Koehler.

Taylor, S. E., \& Brown, J. D. (1994). Positive illusions and well-being revisited: Separating fact from fiction. Psychological Bulletin, 116, 21-27.

Vallerand, R. J., Fortier, M. S., \& Guay, F. (1997). Self-determination and persistence in a real-life setting: Toward a motivational model of high school dropout. Journal of Personality \& Social Psychology, 72(5), 1161-1176.

Vroom, V. H. (1964). Work and motivation. New York: Wiley \& Sons.

Vroom, V. H. (1977). Can leaders learn to lead? In Fiedler, Vroom, \& Argyris (Eds.), Organizational dynamics. New York: American Management Association. 
Vroom, V., Herzberg, F., Kovach, K. A., \& Manz, C. C. (1989). Motivation. In J. Newstrom \& K. Davis (Eds.), Organizational behavior: Readings and exercises (8th ed., chap. 9). New York: McGrawHill.

Vygotsky, L. S. (1978). Mind and society: The development of higher mental processes. Cambridge, MA: Harvard University Press.

Weinberg, R., Gould, D., \& Jackson, A. (1979). Expectations and performance: An empirical test of Bandura's self-efficacy theory. Journal of Sport Psychology, 1, 320-331.

Weiner, B. (1986). History of motivational research in education. Journal of Educational Psychology, 82, 616-622.

Weiner, B. (1990). History of motivational research in education. Journal of Educational Psychology, 82(4), 616-622.

Williams, G., \& Deci, E. L. (1998, August). The importance of supporting autonomy in medical education. Annals of Internal Medicine, 129, 4.

Yelon, S. L. (1996). Powerful principles of instruction. White Plains, NY: Longman.

Patricia L. Hardré, Ph.D., is an assistant professor of instructional psychology and technology at the University of Oklahoma. She teaches graduate courses in instructional design, instructional development and learning systems, instructional technology project management, and educational program evaluation. She has more than 20 years experience in educational program design and development, and 10 in organizational human resource development. Her research interests are in cognition and learning environments, human motivation, and learning and performance assessment, emphasizing links to design practice. 